\title{
Austria
}

\section{Germain Weber}

Professor, University of Vienna, Faculty of Psychology, Department of Clinical, Health and Differential Psychology, Vienna, Austria, email germain.weber@univie.ac.at

$\mathrm{n}$ the past two decades, national as well as regional policy agendas for people with disabilities and especially people with intellectual disabilities have followed strategies of inclusion and rights, with the promotion of a community-based approach.

In the decades before and after the Second World War, support for people with intellectual disabilities was chiefly in the form of large, isolated, public or church-run institutions, with restricted opportunities of self-determination on the part of their residents. Initially, many people with intellectual disabilities lived in such settings from their early years of life. However, after the war, most children with such disabilities entered special educational programmes outside large institutional settings, and continued to live with their families. Emanating mainly from parents' initiatives, the first community-based sheltered workshops were set up for young people with intellectual disabilities during this period. Such initiatives were followed by the establishment of group homes, mainly run by private associations, which allowed people with intellectual disabilities to move out of their family homes.

Following a major reform of the legal regulation on admissions to psychiatric hospitals at the beginning of the 1990s (Hopf \& Aigner, 1993), people with intellectual disabilities moved from psychiatric hospitals to community-based accommodation. Nowadays, the institutional model of care for people with intellectual disabilities is highly contested and largely rejected, for two main reasons. First, during the Second World War, institutions, psychiatrists and psychiatric nurses were actively involved in the Nazis' systematic killing of (among others) people with intellectual disabilities. Second, within the medical model intellectual disability was seen on equal terms with psychiatric disorders. A majority of psychiatric services still operate in line with this traditional view or very close to that line. Only a few mental health service structures have integrated the advances in mental healthcare and intellectual disability. These services follow a community integrated service model for people with such disabilities.

\section{National indicators of prevalence}

Following the Nazis' euthanasia programmes, Austria was reluctant to set up a national register for people with intellectual disabilities. However, Badelt \& Österle (1993) estimated a total population of 48000 , which is similar to an estimate produced by the leading Austrian non-governmental organisation (NGO) in this field, Lebenshilfe Austria, of 47000 (Lebenshilfe, 2006), which is equivalent to a prevalence of $0.6 \%$.

\section{National indicators of mental health problems in intellectual disability}

Health indicators, including of mental health, for people with intellectual disabilities are not established in Austria's national health programme and are not referred to in the national health report (BMGF, 2005; Hofmarcher \& Rack, 2006).

\section{Policy framework and legislation}

People with intellectual disabilities are explicitly referred to in major disability and mental health laws. With respect to admission to psychiatric hospitals, a law of 1991 discriminates between people with mental health problems and people with mental disabilities (i.e. intellectual disabilities): it states that admission to psychiatric hospitals on the basis of a diagnosed intellectual disability alone is illegal. In general, national documents refer to intellectual disability in terms similar to the following:

Individuals with disabilities are persons of any age who are physically, sensorially, mentally or psychologically substantially and persistently impaired in an essential social field. Equal opportunity programmes support people who are in danger of this impairment within a foreseeable time. Essential social fields are, in particular, formal education, vocational training, paid employment, communication, housing and recreation. (BMSSGK, 2003)

There are no national or provincial legal criteria for intellectual disability. In general, a medical certificate is requested attesting an intellectual disability, based upon the classification of the World Health Organization of low intellectual functioning, as defined under F7 of ICD-10 (Dilling et al, 1993).

\section{Policy framework}

The national policy framework is based on human and civil rights, including equal opportunities for people with disabilities affecting essential areas of life.

In general, people with intellectual disabilities and their families are financially supported by various direct and indirect measures. Families with children with disabilities have a right to higher family allowance payments, as long as the child continues to live with them, independent of age. Children and adults with intellectual disabilities are allocated orphans' pensions after the death of their parents. A dependency/nursing allowance is allocated to people with intellectual disabilities according to their level of dependency. Finally, the regional governments financially support people with intellectual disabilities living in group homes, community-based homes or institutional settings.

In general, the financial support from the various sources is managed directly by parents, or the programme's or institution's manager. People with intellectual disabilities, when living outside the parental home, have a right to 'pocket money' (the official term) of $€ 40-70$ per month, depending on the province; to this can be added $€ 40-60$ if the person is admitted on the dependency scheme. In the most western 
regions of Austria 'pocket money' can go up to $€ 250$ per month, depending on the person's capacity for productive work. People with intellectual disabilities are not registered in the general social security programme, as they are offered special allowances, which also cover their health needs.

In summary, the financial support system for people with intellectual disabilities is designed from a perspective of supporting children, which contrasts with disability policies that aim at participation and self-determination during adulthood.

\section{Residential service provision for people with intellectual disabilities and mental health problems}

New assisted accommodation for adults with intellectual disabilities is generally developed in the form of small, community-based homes, typically for 8-12 persons, although some are for individuals or couples. Other options include residential facilities developed many years ago, such as institutional settings for up to 120 persons and group homes for 20-40.

Within the programme of deinstitutionalisation, small community-based homes have been developed in most of the provinces. However, in some regions provision has been outsourced from the hospital system and smoothly adapted to a more individualised, supported residential living community. Recently, in some places, residential service providers have begun to offer special accommodation for people with intellectual disabilities and challenging behaviours.

\section{Mental health services for people with intellectual disabilities and mental health problems}

There is no nationwide structure specialised in the mental health problems of people with intellectual disabilities. In general, large public hospitals covering acute medical needs have generic psychiatric departments. These theoretically also cover the mental health needs of people with intellectual disabilities. However, in reality in most places appropriate services for people with such disabilities are not offered, as professionals are not accustomed to serving that population.

Within the programmes of deinstitutionalisation, the psychiatric centres of some regions have committed themselves to offering in-patient and out-patient support specifically for people with intellectual disabilities, and some are offering training programmes for younger adults with such disabilities and severe challenging behaviour. Such services are examples of best practice with respect to coordination between mental health specialists and community-based small group homes for this population. However, they are still the exception.

\section{Training for mental health professionals on mental health problems in intellectual disability}

Professional groups providing mental healthcare receive little or no specific training in the aetiology and assessment of, or interventions and care for, mental health issues and behavioural problems in people with intellectual disabilities.
For both psychiatrists and clinical psychologists, some training in developmental psychology and the mental health of children with disabilities is offered. However, knowledge and practical training in the area of mental health for adults with intellectual disabilities are not formally covered. In general, the knowledge and experience of intellectual disability of psychiatrists and primary care physicians are very limited, as are those of clinical and health psychologists. This is especially the case when it comes to mental health and behaviour problems. However, psychotherapists have recently become interested in the mental health needs of adults with intellectual disabilities. Moreover, psychotherapy is no longer seen as inappropriate for people with such disabilities by the health insurance system.

\section{Suggested national priorities}

\section{Emerging trends}

O The mental health needs of older and ageing adults with intellectual disabilities will need to be addressed, from psychogeriatrics to emotional assistance at the end of life.

o Formal relationships will need to be developed between residential service providers and specialised psychiatric units with mobile out-patient support for people with intellectual disabilities.

\section{Changes and opportunities}

O Health indicators need to be developed, including mental health indicators for people with intellectual disabilities from a life-span perspective.

O Health and mental health themes, such as prevalence, formal support and outcomes of such support, for people with intellectual disabilities should be included in the national health reports.

O Formal training in intellectual disability should be promoted for psychiatrists, primary health physicians and clinical psychologists, as well as in the training of front-line staff.

o Research on intellectual disability and mental health should be supported.

\section{References}

Badelt, Ch. \& Österle, A. (1993) Zur Lebenssituation behinderter Menschen in Österreich (publication no. 49). [On the living condition of disabled people in Austria.] Ministry of Social Affairs and Generations.

BMGF (Bundesministerium für Gesundheit und Frauen) (Ministry of Health and Women's (issues) (2005) Das Gesundheitswesen in Österreich. [Healthcare in Austria.] BMGF.

BMSSGK (Bundesministerium für Soziale Sicherheit, Generationen und Konsumentenschutz) (Ministry for Social Security, Generations and Consumer Protection) (2003) Bericht der Bundesregierung über die Lage der behinderten Menschen in Österreich. [Government's report on the situation of disabled people in Austria.] BMSSGK.

Dilling, H., Mombour, W. \& Schmidt, M. H. (eds) (1993) WHO: Internationale Klassifikation Psychischer Störungen (ICD-10) Kapitel V (F). Klinisch diagnostische Leitlinien. [WHO: International classification of mental disorders. ICD-10 Chapter V (F). Clinical diagnostic guidelines.] Verlag Hans Huber.

Hofmarcher, M. M. \& Rack, H. M. (2006) Gesundheitssysteme im Wandel: Österreich. [Changes in health systems in Austria.] WHO Regional Office for Europe, commissioned by the European Observatory for Health Systems and Health Politics.

Hopf, G. \& Aigner, G. (1993) Unterbringungsgesetz. [Law regulating admission to psychiatric hospitals.] Manzsche Verlags- und Universitätsbuchhandlung.

Lebenshilfe (2006) Dokumentation zur Anzahl von Menschen mit intellektueller Behinderung in Österreich. [Documentation on figures related to people with intellectual disabilities in Austria.] Lebenshilfe. 